\title{
Balancing between goal-directed and habitual responding following acute stress
}

Citation for published version (APA):

Hartogsveld, B., van Ruitenbeek, P., Quaedflieg, C. W. E. M., \& Smeets, T. (2020). Balancing between goal-directed and habitual responding following acute stress. Experimental Psychology, 67(2), 99-111. https://doi.org/10.1027/1618-3169/a000485

Document status and date:

Published: 01/03/2020

DOI:

10.1027/1618-3169/a000485

Document Version:

Publisher's PDF, also known as Version of record

Document license:

Taverne

Please check the document version of this publication:

- A submitted manuscript is the version of the article upon submission and before peer-review. There can be important differences between the submitted version and the official published version of record.

People interested in the research are advised to contact the author for the final version of the publication, or visit the DOI to the publisher's website.

- The final author version and the galley proof are versions of the publication after peer review.

- The final published version features the final layout of the paper including the volume, issue and page numbers.

Link to publication

\footnotetext{
General rights rights.

- You may freely distribute the URL identifying the publication in the public portal. please follow below link for the End User Agreement:

www.umlib.nl/taverne-license

Take down policy

If you believe that this document breaches copyright please contact us at:

repository@maastrichtuniversity.nl

providing details and we will investigate your claim.
}

Copyright and moral rights for the publications made accessible in the public portal are retained by the authors and/or other copyright owners and it is a condition of accessing publications that users recognise and abide by the legal requirements associated with these

- Users may download and print one copy of any publication from the public portal for the purpose of private study or research.

- You may not further distribute the material or use it for any profit-making activity or commercial gain

If the publication is distributed under the terms of Article $25 \mathrm{fa}$ of the Dutch Copyright Act, indicated by the "Taverne" license above, 


\title{
Balancing Between Goal-Directed and Habitual Responding Following Acute Stress
}

\author{
Bart Hartogsveld ${ }^{1}$, Peter van Ruitenbeek¹,2, Conny W. E. M. Quaedflieg², and Tom Smeets 1,3 \\ 1Department of Clinical Psychological Science, Faculty of Psychology and Neuroscience, Maastricht University, Maastricht, \\ The Netherlands \\ 2Department of Neuropsychology \& Psychopharmacology, Faculty of Psychology and Neuroscience, Maastricht University, Maastricht, \\ The Netherlands \\ ${ }^{3}$ CoRPS - Center of Research on Psychological and Somatic disorders, Department of Medical and Clinical Psychology, Tilburg School of \\ Social and Behavioral Sciences, Tilburg University, Tilburg, The Netherlands
}

\begin{abstract}
Instrumental learning is regulated by two memory systems: a relatively rigid but efficient habit system and a flexible but resourcedemanding goal-directed system. Previous work has demonstrated that exposure to acute stress may shift the balance between these systems toward the habitual system. In the current study, we used a 2-day outcome devaluation paradigm with a $75 \%$ reward contingency rate and altered food reward categories to replicate and extend our previous findings. Participants learned neutral stimulus-response-reward associations on the first day. On the second day, rewards were devalued by eating to satiety. Subsequently, acute stress was induced in half of the participants using the Maastricht Acute Stress Test, while the other half engaged in a nonstressful control task. Finally, relative goal-directed versus habitual behavior was evaluated in a slips-of-action phase, where more slips-of-action indicate a shift toward the habitual system. Results showed that participants successfully acquired the stimulus-response-reward associations, that devaluation was effective, and that stressed participants displayed significant increases in cortisol and blood pressure. Stress led participants to commit more slips-of-action compared with nonstressed controls. The current study extends previous work, showing that the employed paradigm and outcome devaluation procedure are boundary conditions to the stress-induced shift in instrumental responding.
\end{abstract}

Keywords: stress, costisol, habits, instrumental learning
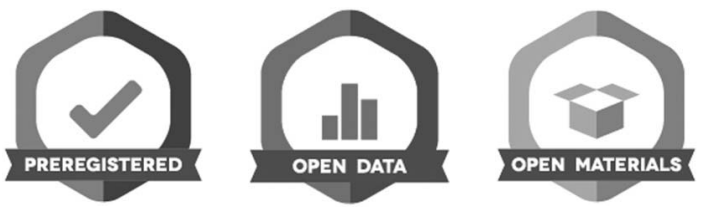

Experiencing stress seems to be an inevitable reality for most organisms, including humans. Successfully dealing with everyday stressful events is therefore of vital importance. When we experience a stressful event, it activates the autonomic nervous system (ANS) and the hypothalamus-pituitary-adrenal (HPA) axis. The faster ANS promotes the secretion of catecholamines (e.g., adrenalin and noradrenalin) from the adrenal medulla within seconds of the event. Although it is fast to respond, its excitation also disappears quickly. The slower HPA axis leads to the release of glucocorticoids (e.g., cortisol), reaching a measurable peak in saliva around $20-40 \mathrm{~min}$ after the onset of the stressful event (Dickerson \& Kemeny, 2004; Joëls \& Baram, 2009). Both the HPA axis and ANS complement each other in mobilizing energy, increasing blood pressure, and having numerous effects on cognitive processes that collectively aim to maximize the chance of survival. Numerous brain structures are regulated downstream by the HPA axis and ANS, including the amygdala (medial and basolateral nuclei), hippocampus, medial prefrontal cortex [ventromedial mPFC (vmPFC)], and a number of limbic structures (Hermans, Henckens, Joëls, \& Fernández, 2014; Pruessner et al., 2008; Ulrich-Lai \& Herman, 2009). Through this interaction, stress has been shown to affect memory processing, concurrently impairing memory retrieval and oftentimes enhancing memory consolidation (Schwabe, 2017). These effects of stress are not always consistent, and they seem dependent on a number of boundary conditions, such as time of administration (e.g., at encoding, consolidation, or retrieval, see Joëls, Fernandez, \& Roozendaal, 2011; Quaedflieg \& Schwabe, 2018), similarities in context of learning and the stressor 
(Shields, Sazma, McCullough, \& Yonelinas, 2017), and relevancy of stimuli to the stressor and/or emotionally charged versus neutral stimuli (Shields et al., 2017; Smeets, 2011).

Recent research has demonstrated that aside from regulating how much we can learn and remember (i.e., memory quantity), stress and stress hormones also influence the way in which multiple memory systems contribute to behavioral performance (i.e., memory quality; Schwabe, Wolf, \& Oitzl, 2010). This is closely related to the influence of stress on instrumental learning. It has been proposed that instrumental learning relies on two parallel memory/learning systems: a relatively rigid but efficient habit system and a more flexible but resourcedemanding goal-directed system. This goal-directed system is mainly responsible for the initial learning of stimulus-response-outcome (S-R-O) associations, while the habit system takes over after enough repetition of the behavior, becoming a stimulus-response (S-R) association (see O’Doherty, Cockburn, \& Pauli, 2017, for a complete review). In their seminal work, Schwabe and Wolf (2009) showed that participants who were exposed to acute stress before learning became insensitive to outcome devaluation. As goal-directed responding is sensitive to outcome devaluation whereas habitual responding is not, this implies that stressed participants had become more habitual in their responses (Schwabe \& Wolf, 2010). Since then, a large number of studies have investigated the role of stress in the habitual and goal-directed system utilizing a variety of paradigms (Alvares, Balleine, \& Guastella, 2014; Otto, Raio, Chiang, Phelps, \& Daw, 2013; Seehagen, Schneider, Rudolph, Ernst, \& Zmyj, 2015; Smeets, van Ruitenbeek, Hartogsveld, \& Quaedflieg, 2019; for a review, see Wirz, Bogdanov, \& Schwabe, 2018). The paradigm that is probably most often used assesses the relative balance between the two systems by means of an instructed devaluation and a slips-of-action task (e.g., de Wit, Niry, Wariyar, Aitken, \& Dickinson, 2007; de Wit et al., 2012; Fournier, d'Arripe-Longueville, \& Radel, 2017; Watson, van Wingen, \& de Wit, 2018). In this outcome devaluation paradigm, participants learn a number of S-R-O associations, after which some of the outcomes are cognitively devalued (i.e., participants were told not to respond to some of the stimuli). In the slips-of-action task, participants are instructed to withhold responses to stimuli that lead to the devalued outcomes ("No-go" trials), while they continue to respond to nondevalued outcomes ("Go" trials). This paradigm differs from the one originally used by Schwabe and Wolf $(2009,2010)$, which implemented a variable reward structure for every trial (using food), more akin to prior animal studies. Schwabe and Wolf also achieved devaluation behaviorally through letting participants eat one of the two types of used food to satiety.
It has recently become apparent that certain boundary conditions apply to existing paradigms. For one, participants in a traditional outcome devaluation paradigm as introduced by de Wit et al. (2007; e.g., Watson et al., 2018) are instructed to collect as many points as possible during the learning stage before devaluation, and these are earned based on task performance (speed and accuracy). However, like some have proposed (e.g., De Houwer, Tanaka, Moors, \& Tibboel, 2018), this could mean that earning points is, in fact, the most important goal for participants. We therefore cannot be certain that differences in responding are, in fact, the result in a shift toward new goals of the goal-directed system or solely reflect habitual responding. Similar limitations also apply to other paradigms (see De Houwer et al., 2018; Watson \& de Wit, 2018). In a recent paper, we tried to resolve some of these issues. We used two different paradigms to elicit a shift in the balance between the goal-directed and habitual system. The first study used a paradigm similar to a traditional outcome devaluation paradigm (e.g., Watson et al., 2018). In the second study, we introduced an additional behavioral devaluation procedure and occasional food rewards in the learning stage (Smeets et al., 2019). These changes (partially) resolved the reliance on points, thereby making a sole reduction in goal-directed control less likely. While both paradigms yielded similar results, stress did not unambiguously cause a shift in balance between the goaldirected and habitual systems. Only stressed participants who displayed a clear-cut cortisol response (larger than 1.5 nmol/L; see Miller, Plessow, Kirschbaum, \& Stalder, 2013) displayed more responses toward devalued outcomes compared with nonstressed controls. This further indicates that acute stress-induced cortisol reactivity might be an additional boundary condition in outcome devaluation paradigms.

In this study, we aimed to replicate and extend our previous findings in three important ways. First, as acute stress promotes the formation of enduring memories by enhancing memory consolidation (e.g., Smeets, Otgaar, Candel, \& Wolf, 2008) but at the same time impairs memory retrieval processes (e.g., see Shields et al., 2017), it is imperative to separate the learning and memory expression phases of instrumental learning tasks (cf., Fournier et al., 2017) by employing a 2-day instrumental learning paradigm. This also capitalizes on longer-term learning through extension of the memory consolidation time window, since this window can last up to a few hours (Dudai, 2004). Second, we allowed participants to choose their favorite types of food from two more distinct and roughly equally valued food types (crisps and chocolate). This was done to maximize the subjective reward value for the participants, therefore promoting learning and making sure both food types can be equally devalued (for an 
overview of the role of reward value in learning, see, for example, Schultz, 2015). Third, a 75\% contingency rate was chosen to match the original instrumental learning paradigm by Schwabe and Wolf (2010). It is well established (e.g., Sheffield, 1949; Weinstock, 1954) that a partial reinforcement schedule like this one reduces the extinction rate of the learned associations, making them available for a longer amount of time. Partial reinforcement schedules are therefore preferred in selective devaluation paradigms and sequential decision-making tasks (e.g., Friedel et al., 2014). We expect, like in our previous work, to find a difference between the stress group (to which acute stress was administered) and the no-stress control group on the number of responses made to items associated with devalued outcomes, indicative of a shift away from the goal-directed system toward habits, but only in cortisol responders.

\section{Method}

\section{Participants}

A power analysis was done with GPower (Erdfelder, Faul, $\&$ Buchner, 1996) with power $(1-\beta)$ set at .80 , $\alpha$ set at .05 , and effect size in $f$ set to .33 obtained from our previous study (see Study 2 in Smeets et al., 2019), for a repeated measures within-between interaction, two groups and two measurements (correlation among these of -.389, obtained from the first 25 data points). This showed that we needed a total sample size of 54. Eighty-one healthy undergraduates (20 men, 60 women, 1 unknown due to missing data) enrolled in the study. Sixteen participants were excluded (see the Statistical Analysis section), bringing the total down to 65 (18 men, 47 women), with a mean age of 22.20 (range $=18-30 ; S D=2.97$ ) and a mean BMI of 21.92 (range $=17.84-29.22 ; S D=2.49$ ). After the first testing day, participants were semirandomly allocated to either a stress group ( $n=30 ; 6$ men, 24 women) or a nostress control group ( $n=35 ; 12$ men, 23 women). Participants who had already experienced a similar stress manipulation in the past [e.g., (Socially Evaluated) Cold Pressor Test, Maastricht Acute Stress Test (MAST)] were allocated to the no-stress group. Groups did not differ significantly in age $(U=513.50 ; p=.879)$, BMI $(U=488.00$; $p=.767)$, or distribution of men and women $\left(\chi_{(1, N=65)}^{2}=\right.$ 1.646 ; $p=.199)$. Participants were screened in a semistructured interview on having allergies or dietary restrictions for the foods present in the study and on the following factors that are known to affect the HPA axis: physical illnesses (cardiovascular or endocrine disorders, other severe illnesses such as fibromyalgia), current or recent $(<1$ year ago) psychological disorders, frequent substance abuse, heavy smoking ( $>10$ cigarettes/day), or taking certain types of medication (e.g., psychoactive). All participants were recruited via advertisements requesting volunteers for a study that could include being in a physically or mentally demanding situation. They received a small financial compensation or partial course credit for their participation. This study was approved by the standing ethics committee of the Faculty of Psychology and Neuroscience, Maastricht University, complying with the Declaration of Helsinki (v. 2013).

\section{Procedure}

See Figure 1 for the timeline of the second day of the study. Participants were tested between 12:00 and 4:00 p.m. on both test days, but not necessarily at the exact same time. The two sessions on two consecutive days lasted for $2 \mathrm{hr}$ in total (first session: $45 \mathrm{~min}$; second session: $1 \mathrm{hr} 15 \mathrm{~min}$ ). They were asked to refrain from taking alcohol on days of testing and the previous day after 7:00 p.m. and to sleep minimally for $6 \mathrm{hr}$. To minimize variation in the saliva cortisol measures, participants were asked to not consume any food and any liquids except nonsparkling water $2 \mathrm{hr}$ before testing, to not smoke and brush their teeth $2 \mathrm{hr}$ before testing, to not undertake any strenuous exercise $24 \mathrm{hr}$ before testing, and to not take over the counter medication the days of testing and 2 days before those.

On the first day, after reading information on the study and providing written informed consent, compliance with the guidelines was checked. After this, participants completed two visual analog scales (VAS) on their current hunger status (How hungry are you at the moment? and Do you feel like eating something tasty?; anchors: $0=$ not at all hungry and not at all to $100=$ very hungry and very much so). They then chose their three favorite types of chocolate snacks and three favorite types of crisps (both out of eight possible types). Types of chocolate snacks to choose from were KitKat regular (Nestlé S.A.), Bounty (Mars Inc.), Lion regular (Nestlé S.A.), Toblerone milk (Mondelēz Int.), Belgian chocolates (Baronie, NV), Twix regular (Mars, Inc.), Milka milk flavor (Mondelēz Int.), and Mars bars (Mars, Inc.). Types of crisps were Lay's paprika, Lay's classic, Doritos nacho cheese, Cheetos Nibb-it sticks, Cheetos Nibb-it rings, Bugles nacho cheese, Lay's Wokkels paprika, and Lay's Hamka's (all PepsiCo, Inc.). The participants then completed eight blocks of the instrumental learning stage (see below). After each second block, a small test was taken of their knowledge of S-R-O associations. Participants were misleadingly told that if they learned the associations above a certain threshold level (not specified further), they would receive food rewards. In 


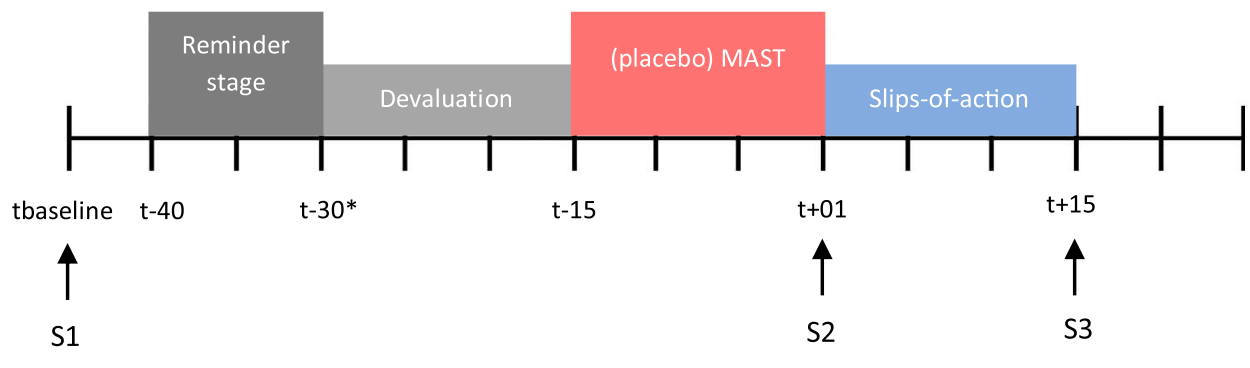

Figure 1. Timeline for the second day of the study. S1, S2, and S3 indicate the three saliva samples taken ( $\left.t_{\text {baseline }}, t_{+01}, t_{+15}\right)$ at the beginning of the testing day, 1 , and 15 min after the end of the (placebo) Maastricht Acute Stress Test (MAST). Duration of the devaluation phase (the actual time participants were eating) was somewhat variable, and some participants ate slower and/or more than others $(*)$.

reality, all participants received a small food reward (one of their chosen types of chocolate and one of the crisps, each weighing only a few grams), regardless of their performance. They then completed a VAS on their evaluation of the received food [How much do you like (i.e., enjoy the taste of) this piece of chocolate? and How much do you like (i.e., enjoy the taste of) these crisps?; anchors: $\mathrm{O}=$ not at all to $100=$ very $m u c h]$. After completing these, participants completed the same VAS on their current hunger status. All VAS scores were administered through pen and paper on a $10-\mathrm{cm}$ long line.

On the second day, compliance with the guidelines was checked again. After this, a first saliva sample and their vital signs (blood pressure and heart rate; always on the right arm) were taken using an automatic blood pressure monitor (OMRON 705IT; OMRON Healthcare Europe B.V.). After the hunger VAS, participants completed two reminder blocks of the instrumental learning stage, identical to those of the first day, including the S-R-O knowledge test. Then, one of the types of food was randomly assigned to be devalued. First, it was behaviorally devalued: Participants were told that they had to eat the first amount presented to them (50 g, consisting of their three chosen types) and eat as much as possible of the second amount (200 g, until satiation). They were provided with as much water as they wanted during this phase. They then completed a VAS on their liking of their eaten food. After rinsing their mouth with water thoroughly, they completed the stress/control MAST procedure (50 min after the baseline saliva measurement). Directly afterward, their vital signs were taken and then another saliva sample, and they then completed a VAS on their experienced stress in the task (How stressful did you find the recently completed (water and counting) task to be?, How painful ...?, and How unpleasant ...?; anchors: $0=$ not at all stressed, no pain at all, and extremely pleasant to $100=$ extremely stressed, worst pain imaginable, and extremely unpleasant). The stress/control MAST procedure took place after the reminder stage and behavioral devaluation, and the paradigm was optimized to have the slips-of-action stage cooccur with the expected peak in salivary cortisol elicited by the MAST (Smeets et al., 2012). Before the slips- of-action stage, the behaviorally devalued food type was now cognitively devalued: Participants were told to not respond to the devalued food type (No-go) but to still respond to the valuable food type (Go). The onset of the slips-of-action stage was approximately $5 \mathrm{~min}$ after the end of the MAST procedure. Afterward, their vital signs were taken and the last saliva sample (15 min after MAST), and then, the last hunger and willingness-to-eat VAS were filled out. Last, participants were fully debriefed and reimbursed for their participation.

\section{Stress Versus No-Stress Control Procedure}

The stress group was exposed to the MAST (Smeets et al., 2012) combining both psychological and physical components. After a 5-min instruction phase, participants were asked to repeatedly insert their left hand in ice-cold water $\left(2^{\circ} \mathrm{C}\right)$, alternated with counting backward in steps of 17 starting at 2,043 as fast and accurately as possible. Each time they made a mistake during the counting, they received negative feedback (e.g., incorrect or faster). Participants were also told they were being videotaped (having to look at their own face on the monitor). They were instructed that the recording was later used for facial analysis, while, in fact, nothing was being recorded. This stress phase lasted for $10 \mathrm{~min}$.

The control group completed the placebo MAST, a validated control condition (Smeets et al., 2012, Exp. 3) that is equal in length and with similar operations as the stress MAST. Participants were asked to insert their hand in lukewarm water $\left(36^{\circ} \mathrm{C}\right)$ and performed a simple counting task without being videotaped (both the monitor and camera were covered, obscuring them from view) or receiving negative feedback. The counting task consisted of counting from 1 to 25 , out loud in a chosen comfortable tempo, over and over again until the hand in water trial started again.

\section{Neuroendocrine Stress Responses}

Salivary cortisol was sampled via synthetic Salivette (Sarstedt ${ }^{\circledast}$, Etten-Leur, The Netherlands) devices at the 
start ( $\left.t_{\text {baseline }}\right)$ and 1 and 15 min after the end of the stress/ control procedure $\left(t_{+01}\right.$ and $\left.t_{+15}\right)$. Samples were stored at $-20{ }^{\circ} \mathrm{C}$ immediately after collection. Cortisol levels were determined by a chemiluminescence immunoassay (IBL Intl., Hamburg, Germany) with mean intra- and interassay coefficients of variation $<8 \%$.

\section{Instrumental Learning Task}

Participants performed an instrumental learning task on both days, consisting of an instrumental learning stage (including a reminder stage), a selective devaluation phase, and a slips-of-action stage. In the instrumental learning stage, participants had to learn six different S-R-O associations by trial-and-error. Participants were instructed to respond as accurately and fast as possible, thereby accumulating as many points as possible. At the beginning of each trial, a box was displayed with a block pattern on it (consisting of three black squares on a three-by-three grid; see Figure 2), after which participants had to respond with either a key press using their left index finger (" 1 " key on the keyboard) or right index finger (" 6 " key on the keyboard). Each pattern had only one correct key and one associated food (one of the six food stimuli that were chosen by the participant beforehand). For half of the boxes (i.e., 3), the "1" key was the correct key, and for the other half, the " 6 " key was the correct key, equally distributed. If the participant pressed the correct key, the box would open, the food would be inside the box, and they received a number of points based on their response time (ranging from 1 to 5 ). If they pressed the incorrect key, the box would also open, but no food would be inside and they did not receive any points. Participants were told that this stage had a $75 \%$ contingency rate, meaning that $25 \%$ of the time correct buttons would result in the incorrect button scenario. The task was self-paced, and each S-R$\mathrm{O}$ combination was randomly presented four times per block, resulting in eight blocks of 24 trials, and 192 trials in total. Likewise, the reminder stage on the second testing day consisted of two blocks of 24 trials ( 48 trials in total). After each block, their cumulative points' total was shown on screen. After each second block, the explicit knowledge test was administered. This test consisted of two open-ended questions per block pattern (12 in total). Participants had to indicate the correct button for each pattern (left or right) and the food that was associated with that pattern and thus inside the box during the task.

After the devaluation phase on the second testing day (see the Procedure section), participants proceeded to the
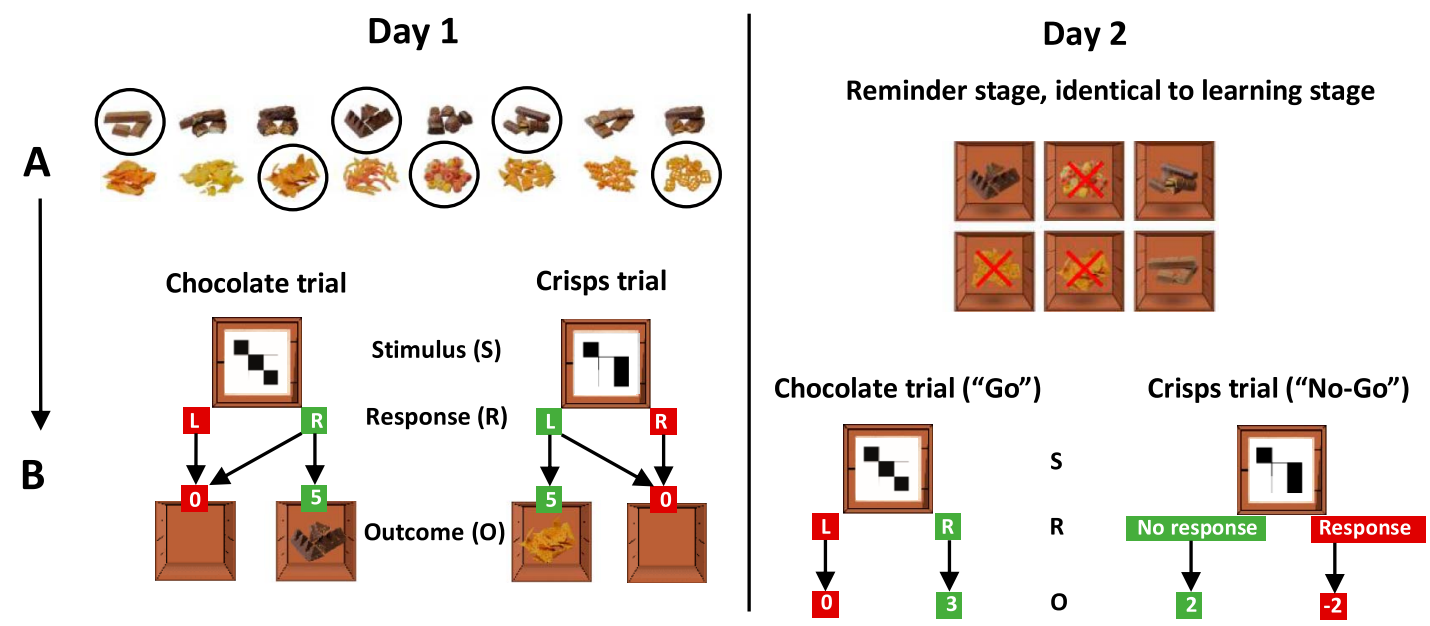

Figure 2. Overview of the tasks on Day 1 and Day 2. On Day 1, participants could first choose three of their favorite types of food for both crisps and chocolate (Day 1, A) that were used in the subsequent tasks. In the learning stage (Day 1, B), participants had to learn associations between stimuli (block patterns), a correct response (left or "1" for three of the block patterns, right or "6" for the other three patterns), and an outcome ( 0 or 5 points, plus an image of the food inside the box). In $25 \%$ of the trials where the correct button was pressed, the outcome for incorrect trials was shown. This learning stage consisted of eight blocks, 24 trials per block. On the second day, a reminder stage identical to the learning stage was completed by the participant (Day 2, A), consisting of two blocks of 24 trials per block. After the devaluation and (placebo) Maastricht Acute Stress Test (MAST), participants performed the slips-of-action stage. First, an image was presented (Day 2, A) that showed the devalued food type (here crisps). Participants then completed four blocks of 24 trials per block where the boxes did not open anymore; hence, they did not get any feedback on their performance in this block. For the devalued food type (No-go), any response (whether previously correct or not) resulted in negative points. For the still valuable food type (Go), the task was essentially identical to the learning stage and reminder stage. 
slips-of-action stage. At the beginning of each block, participants were shown an overview of all six food types for $12 \mathrm{~s}$, with a red cross superimposed on the three devalued food items of one of the types of food. They were again instructed to respond as accurately and fast as possible. Here, they were also instructed that responding to the three block patterns associated with the devalued food type (either crisps or chocolate) now resulted in losing points (No-go trials). Thus, they had to withhold their response to half of the stimuli. The other type still awarded points (Go trials) and required the participant to respond with a previously learned button press. They were also instructed that the boxes would no longer open as to not give them feedback on whether they were correct that would potentially allow relearning of the associations. Their cumulative points' total was still shown after each block, however. All stimuli were randomly shown four times per block again, resulting in four blocks of 24 trials, and 96 trials in total.

\section{Statistical Analysis}

Sixteen participants in total were excluded from the initial sample for the following reasons: Eight participants were excluded due to missing data and computer malfunction on the second day. An additional four participants were excluded for being outliers on the baseline cortisol measurement, irrespective of groups (stress $n=3$, no-stress control $n=1$ ). These were calculated using the median absolute difference (double, correcting for skewness) with a cutoff value of 3.5 (Leys, Ley, Klein, Bernard, \& Licata, 2013; Rousseeuw \& Croux, 1993). We excluded two participants for not learning the associations correctly according to the explicit knowledge test (no-stress control $n=2$ ). Last, we excluded two additional participants who performed near chance level on the amount of responding on valued trials on the slips-of-action stage (stress $n=1$, no stress control $n=1$ ).

The data of the final sample $(N=65)$ were checked for normality with $\mathrm{Q}-\mathrm{Q}$ plots, skewness values, and kurtosis values. Since the cortisol data were nonnormally distributed, they were log transformed for inferential statistical analysis. Cortisol, heart rate, and blood pressure data were analyzed with 2(Group: stress vs. control) $\times 3$ (Time: $\left.t_{\text {baseline, }}, t_{+01}, t_{+15}\right)$ mixed ANOVAs, with Time as a repeated measure and Group as a between-subject factor. To examine the role of acute stress-induced cortisol reactivity, cortisol increases after the stress/control procedures were computed relative to cortisol baseline values. In line with previous studies (Smeets et al., 2019), participants in the stress group were characterized as cortisol responders when displaying a cortisol increase equal to or larger than $1.5 \mathrm{nmol} / \mathrm{L}$ (Miller, Plessow, Kirschbaum, \& Stadler, 2013) and as nonresponders when having an increase smaller than $1.5 \mathrm{nmol} / \mathrm{L}$. This resulted in a group distribution of 23 cortisol responders and 7 cortisol nonresponders. Group allocation was then confirmed by calculating the Area Under the Curve with respect to increase (AUCi; Pruessner, Kirschbaum, Meinlschmid, \& Hellhammer, 2003) for each participant individually, as a single measure of the total cortisol concentration from baseline. The following formula was used to compute AUCi: $\left\{\left[\left(t_{\text {baseline }}+\right.\right.\right.$ $\left.\left.\left.t_{+01}\right) / 2\right] \times 50\right\}+\left\{\left[\left(t_{+01}+t_{+15}\right) / 2\right] \times 15\right\}-\left[t_{\text {baseline }} \times(50+\right.$ 15)]. We then performed a three-level (ResponderGroup: cortisol responders vs. cortisol nonresponders vs. controls) univariate ANOVA to test whether the groups differed on their total cortisol concentration from baseline (AUCi).

Learning rates for the S-R-O associations were assessed using mixed ANOVAs for group on the learning stage using a 2(Group) $\times$ 8(BlockLearning: B1-B8). We analyzed reminder stage learning rates similarly using a 2(Group) $\times$ 2(BlockReminder: B1-B2) mixed ANOVA. For both the learning and reminder stages, we assessed whether there was a difference if we split up the stress group into cortisol responders and cortisol nonresponders using 3(ResponderGroup) as a between-subject factor instead of 2(Group). Last, to confirm these learning rates, the same analyses were run on the explicit knowledge test presented after each second block. The number of questions correct per test after each second block (maximum of six questions correct) were analyzed with two mixed ANOVAs, namely, one for the questions on the correct button and one for the questions for the food inside the box. These mixed ANOVAs were run for both 2(Group) and 3(ResponderGroup).

Effectiveness of the devaluation procedure was determined by assessing the amount eaten during devaluation and hunger- and willingness-to-eat ratings on a VAS. These were analyzed using 2(Group) and 3(ResponderGroup) univariate ANOVAs for amount eaten and 2 (Group) $\times 2$ (Time: predevaluation vs. postdevaluation) and 3(ResponderGroup) $\times$ 2(Time: predevaluation vs. postdevaluation) mixed ANOVAs for both hunger- and willingness-to-eat ratings.

The balance between habitual and goal-directed responses was assessed through percentage responses made in the slips-of-action stage using 2(Group: stress vs. control) $\times$ 2(Value: devalued vs. valuable) and 3(ResponderGroup) $\times$ 2(Value: devalued vs. valuable) mixed ANOVAs. Reaction times per group were checked with mixed ANOVAs for anomalies for all stages (learning, reminder, slips-of-action). Greenhouse-Geisser corrected $p$ values are reported when sphericity assumptions are violated, and the Holm-Bonferroni method was used to correct for multiple comparisons in simple effects and follow-up tests (Holm, 1979). 


\section{Results}

\section{Neuroendocrine Stress Responses}

Cortisol responses can be seen in Figure 3A for the stress and no-stress control groups. We found a significant difference between the stress and no-stress control group in stress responses across the different time points (Group $\times$ Time interaction: $\left.F_{(1.358,}, 85.583\right)=28.924, p<.001$, $\left.\eta_{\mathrm{p}}^{2}=.315\right)$, with only the stress group showing a significant increase across the different time points. Simple effects showed that groups did not differ significantly on $t_{\text {baseline }}$ $\left(F_{(1,63)}=.339, p_{\text {corrected }}=.563\right)$, but the stress group showed a higher cortisol response than no-stress controls on both $t_{+01}\left(F_{(1,63)}=10.579, p_{\text {corrected }}=.004\right)$ and $t_{+15}\left(F_{1,63}=\right.$ $37.353, p_{\text {corrected }}<.001$ ). Likewise, cortisol responders (see Figure $3 \mathrm{~B}$ ) differed from cortisol nonresponders and nostress controls on their AUCi value (ResponderGroup: $\left.F_{(2,62)}=17.631, p<.001, \eta_{\mathrm{p}}^{2}=.363\right)$. Follow-up tests showed a higher AUCi value in cortisol responders compared to no-stress controls $\left(F_{(1,56)}=26.594, p_{\text {corrected }}<\right.$ $.001)$ and cortisol nonresponders $\left(F_{(1,28)}=13.791, p_{\text {corrected }}\right.$ $=.002)$, who did not differ from each other $\left(F_{(1,40)}=1.819\right.$, $\left.p_{\text {corrected }}=.185\right)$.

See Table 1 for the results of the analyses of the diastolic blood pressure data. A significant interaction was found for both Group and ResponderGroup (Group $\times$ Time interaction: $F_{(2,62)}=8.182, p=.001, \eta_{\mathrm{p}}^{2}=.209 ; F_{(4,122)}=$ $4.501, p=.002, \eta_{\mathrm{p}}^{2}=.129$, respectively). Simple effects showed that the stress group increased significantly in diastolic blood pressure compared to the decrease in nostress controls, but only on $t_{+01}\left(F_{(1,63)}=7.471, p_{\text {corrected }}=\right.$ $.024)$, not on $t_{\text {baseline }}\left(F_{(1,63)}=7.471, p_{\text {corrected }}>.921\right)$ or $t_{+15}$ $\left(F_{(1,63)}=.004, p_{\text {corrected }}=.951\right)$. Follow-up tests for ResponderGroup revealed a higher blood pressure of cortisol nonresponders compared to no-stress controls on $t_{+01}\left(F_{(1,40)}=11.803, p_{\text {corrected }}=.013\right)$, but not on $t_{\text {baseline }}$ or $t_{+15}$. Likewise, there was no difference between cortisol nonresponders and responders or between cortisol responders and no-stress controls (on all time points). There was no significant difference between the groups in heart rate and systolic blood pressure, irrespective of whether stress and no-stress controls or cortisol nonresponders and cortisol responders were compared.

\section{Instrumental Learning Stage}

Performance increased significantly over the eight learning blocks (BlockLearning: $F_{(3.941,244.360)}=106.105$, $\left.p<.001, \eta_{\mathrm{p}}^{2}=.631\right)$. All groups reached near-ceiling levels of accuracy around the seventh block and remained high

\section{Cortisol}

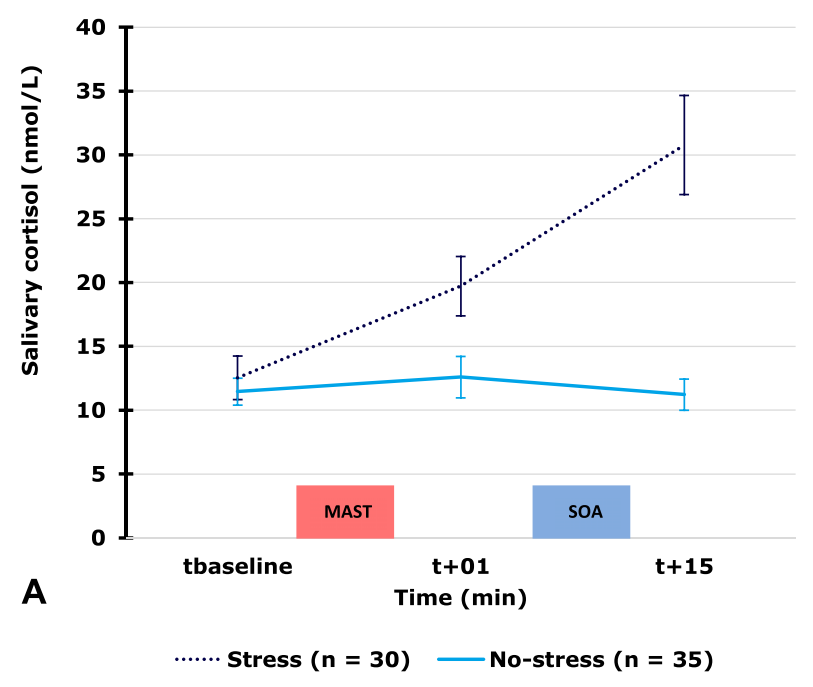

Cortisol

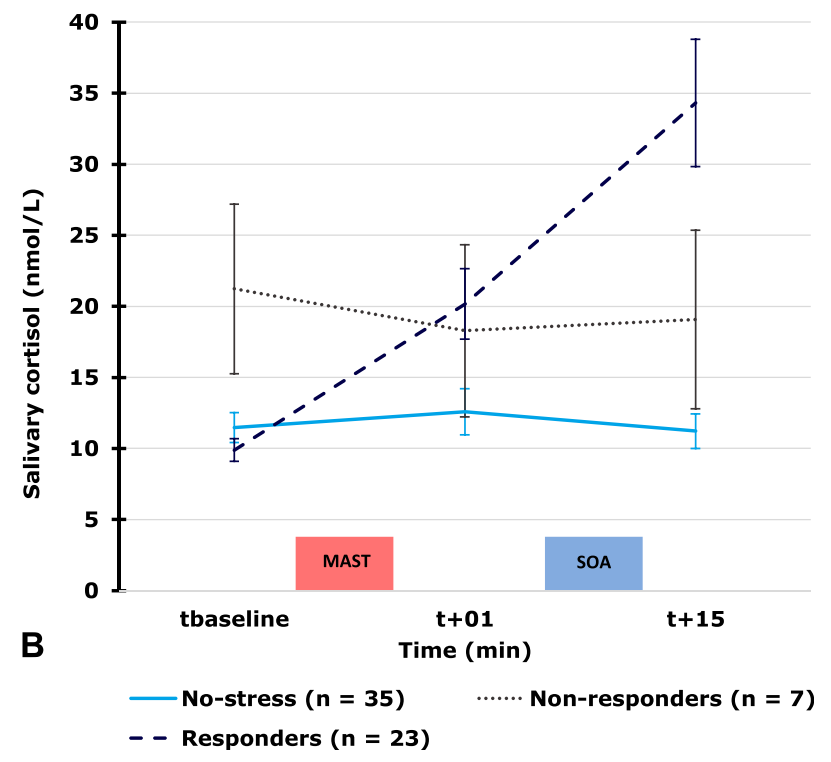

Figure 3. (A) Cortisol responses for the stress and no-stress control group. Salivary cortisol measurements are nonlog corrected means for visual clarity $( \pm S E)$. First opaque bar represents where the MAST was performed (between $t_{\text {baseline }}$ and $t_{+01}$ ), and the second represents where the slips-of-action (SOA) stage was performed (between $t_{+01}$ and $\left.t_{+15}\right)$. (B) Cortisol responses for the no-stress control, cortisol nonresponders ( $<1.5 \mathrm{nmol} / \mathrm{L}$ increase) and cortisol responders (>1.5 nmol/L increase). Salivary cortisol measurements are nonlog corrected means for visual clarity $( \pm S E)$. First opaque bar represents where the MAST was performed (between $t_{\text {baseline }}$ and $t_{+01}$ ), and the second represents where the SOA was performed (between $t_{+01}$ and $t_{+15}$ ). MAST = Maastricht Acute Stress Test.

afterward (see Figure 4). Reaction times decreased similarly across all groups in the learning stage as expected (Block: $\left.F_{(2.736,169.648)}=41.856, p<.001, \eta_{p}^{2}=.403\right)$, indicating that all groups successfully acquired S-R-O contingencies. This was confirmed by analysis of the explicit 
Table 1. Mean diastolic blood pressure for no-stress controls, stress, cortisol responder, and cortisol nonresponder groups for $t_{\text {baseline }}, t_{+01}$, and $t_{+15}$ (SE)

\begin{tabular}{lcccr}
\hline & Control group $(n=35)$ & Stress group $(n=30)$ & Responder group $(n=23)$ & Nonresponder group $(n=7)$ \\
\hline Diastolic $t_{\text {baseline }}$ & $71.31(1.16)$ & $71.53(1.96)$ & $69.09(1.91)$ & $79.57(4.64)$ \\
Diastolic $t_{+01}$ & $67.37(1.33)$ & $73.63(1.93)$ & $71.87(2.07)$ & $79.43(4.28)$ \\
Diastolic $t_{+15}$ & $68.00(1.41)$ & $68.13(1.68)$ & $66.74(1.93)$ & $72.71(2.94)$ \\
\hline
\end{tabular}

\section{Learning rate}

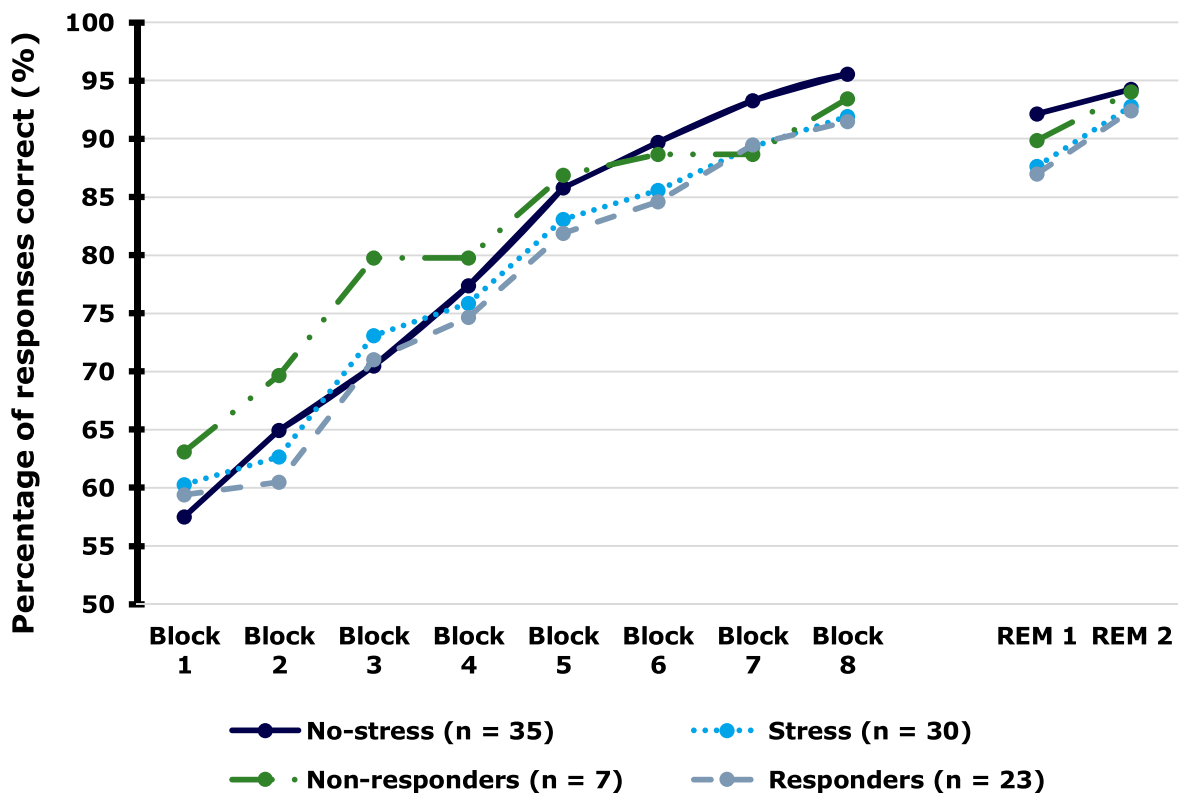

Figure 4. Learning rates for the instrumental learning stage (Blocks 1-8) and reminder stage (REM1-REM2), displayed in mean percentage of responses that was correct during both stages. Results are displayed for the no-stress control, stress, cortisol nonresponder, and cortisol responder groups separately. knowledge test that was done on the correct button (Block: $\left.F_{(2.265,142.664)}=44.658, p<.001, \eta_{\mathrm{p}}^{2}=.415\right)$ and on the outcome food (Block: $F_{(2.526,159.109)}=110.581, p<.001, \eta_{\mathrm{p}}^{2}=.637$ ).

There was no significant difference between the stress group and no-stress control group in the percentage of responses that were correct in the instrumental learning stage $\left(\right.$ Group $\times$ BlockLearning interaction: $F_{(3.941,244.360)}=$ $\left.1.251, p=.290, \eta_{\mathrm{p}}^{2}=.020\right)$. When comparing cortisol responders, cortisol nonresponders, and no-stress controls, the same pattern was found (ResponderGroup $\times$ BlockLearning interaction: $F_{(7.843,239.201)}=.908, p=.509$, $\eta_{\mathrm{p}}^{2}=.029$; BlockLearning: $F_{3.921,239.201}=61.456, p<.001$, $\eta_{\mathrm{p}}^{2}=.502$; see Figure 4 ).

\section{Reminder Stage}

Similar to the learning stage, for the reminder stage on Day 2 , accuracy remained high across all groups, and there was no difference in the explicit knowledge test, indicating that participants successfully retained the S-R-O contingencies. For the percentage correct responses, the Group $\times$ BlockReminder interaction was significant $\left(F_{(1,63)}=5.074\right.$, $\left.p=.028, \eta_{\mathrm{p}}^{2}=.075\right)$. Follow-up simple effects revealed that there were no significant group differences on Block 1 $\left(F_{(1,63)}=2.283, p_{\text {corrected }}=.272, \eta_{\mathrm{p}}^{2}=.035\right)$ nor on Block 2 $\left(F_{(1,63)}=.248, p_{\text {corrected }}>.999, \eta_{\mathrm{p}}^{2}=.035\right)$. There were also no differences between responders, nonresponders, and no-stress controls (ResponderGroup $\times$ BlockReminder: $\left.F_{(2,62)}=2.646, p=.079, \eta_{\mathrm{p}}^{2}=.079\right)$.

\section{Devaluation}

See Table 2 for the results of amount eaten and hungerand willingness-to-eat VAS ratings. Both hunger VAS (Time: $\left.F_{(1,61)}=71.554, p<.001, \eta_{\mathrm{p}}^{2}=.540\right)$ and willingness-to-eat VAS (Time: $F_{(1,61)}=46.312, p<.001$, $\eta_{\mathrm{p}}^{2}=.432$ ) decreased significantly after devaluation, indicating that it was successful in all groups. For Group analysis, both hunger VAS (Group $\times$ Time interaction: $\left.F_{(1,61)}=.771, p=.383, \eta_{\mathrm{p}}^{2}=.012\right)$ and willingness-to-eat VAS (Group $\times$ Time interaction: $F_{(1,61)}=.495, p=.485$, $\left.\eta_{\mathrm{p}}^{2}=.008\right)$ were not significant, indicating that devaluation did not differ between groups. This was also the case for ResponderGroup analyses, and hunger VAS (Group $\times$ 
Table 2. Mean amount of food eaten during devaluation in grams, pre- and postdevaluation hunger, and willingness-to-eat ratings (0-100) of the stress and no-stress control group (SE)

\begin{tabular}{lcccc}
\hline & Control group $(n=35)$ & Stress group $(n=30)$ & Responder group $(n=23)$ & Nonresponder group $(n=7)$ \\
\hline Amount of food eaten & $85.73(7.65)$ & $69.37(5.23)$ & $72.35(6.51)$ & $59.57(5.90)$ \\
Predevaluation hunger & $66.39(4.23)$ & $62.65(4.38)$ & $63.78(5.04)$ & $58.93(9.45)$ \\
Postdevaluation hunger & $33.18(3.74)$ & $35.68(4.16)$ & $36.09(4.25)$ & $34.36(11.85)$ \\
Predevaluation willingness-to-eat & $73.56(3.65)$ & $68.33(4.12)$ & $68.87(4.74)$ & $66.57(9.00)$ \\
Postdevaluation willingness-to-eat & $45.55(4.21)$ & $45.57(4.56)$ & $47.24(5.25)$ & $40.07(9.57)$ \\
\hline
\end{tabular}

Time interaction: $\left.F_{(2,60)}=.412, p=.664, \eta_{\mathrm{p}}^{2}=.014\right)$ and willingness-to-eat VAS (Group $\times$ Time interaction: $F_{(2,60)}=$ $\left..316, p=.731, \eta_{\mathrm{p}}^{2}=.010\right)$ were not significant. There was no significant difference in amount eaten resulting from both Group $\left(F_{(1,63)}=3.259, p=.076, \eta_{\mathrm{p}}^{2}=.049\right)$ and ResponderGroup $\left(F_{(2,62)}=1.923, p=.155, \eta_{\mathrm{p}}^{2}=.058\right)$ ANOVAs.

\section{Slips-of-Action Stage}

See Figure 5A for the results of the slips-of-action stage in the stress and no-stress control groups. A significant difference between the stress and no-stress control groups was obtained when comparing the balance between responding to valuable and devalued outcomes (Group $x$ Value: $\left.F_{(1,63)}=7.677, p=.007, \eta_{\mathrm{p}}^{2}=.109\right)$. Simple effects revealed that in comparison to nonstressed controls, stressed participants made more responses toward devalued outcomes $\left(F_{(1,63)}=6.256, p_{\text {corrected }}=.030\right.$, $\left.\eta_{\mathrm{p}}^{2}=.081\right)$ and fewer responses toward still valuable outcomes $\left(F_{(1,63)}=5.194, p_{\text {corrected }}=.026, \eta_{\mathrm{p}}^{2}=.076\right)$. We also found a significant difference (see Figure 5B) between the no-stress controls, cortisol responders, and cortisol nonresponders on making responses toward still valuable and devalued outcomes (ResponderGroup $\times$ Value: $F_{(2,62)}=$ $\left.4.114, p=.021, \eta_{\mathrm{p}}^{2}=.117\right)$. Follow-up tests revealed that no effects survived Holm-Bonferroni correction, neither for valuable outcomes (nonresponders vs. responders: $F_{(1,28)}=$ $.005, p_{\text {corrected }}=.943$; controls vs. responders: $F_{(1,56)}=5.257$, $p_{\text {corrected }}=.128$; controls vs. nonresponders: $F_{(1,40)}=2.627$, $p_{\text {corrected }}=.452$ ) nor for devalued outcomes (nonresponders vs. responders: $F_{(1,28)}=.451, p_{\text {corrected }}>.999$; controls vs. responders: $F_{(1,56)}=6.918, p_{\text {corrected }}=.066$; controls vs. nonresponders: $\left.F_{(1,40)}=2.544, p_{\text {corrected }}=.356\right)$.

\section{Discussion}

In this study, we further modified the slips-of-action paradigm in an attempt to replicate previous findings, showing that a slips-of-action paradigm can be used to shift the balance toward habitual responding and/or away from goal-directed responding after acute stress (Fournier et al., 2017; Smeets et al., 2019). We also attempted to extend these findings by investigating boundary conditions, specifically testing a two-day paradigm, introducing a $75 \%$ contingency rate, and asking participants their favorite foods beforehand. Participants learned the S-R-O associations well as revealed by their accuracy and reaction time across the blocks, reaching a high level of accuracy in the last few blocks. We observed similar patterns in the reminder stage, showing that a 2-day paradigm is viable, since all groups remembered the associations sufficiently after the learning stage. In accordance with previous studies (e.g., Quaedflieg, Meyer, van Ruitenbeek, \& Smeets, 2017; Quaedflieg, Stoffregen, Sebalo, \& Smeets, 2019; Shilton, Laycock, \& Crewther, 2017; Smeets et al., 2012), participants exposed to the MAST showed a significant increase in salivary cortisol compared to the no-stress control group, on both $t_{+01}$ and $t_{+15}$, and no group differences were observed

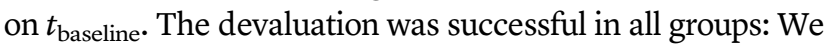
observed a decrease in willingness-to-eat and hunger ratings after the devaluation procedure. In the slips-of-action stage, participants in the stress group made fewer responses toward obtaining valuable outcomes. More importantly, they also made more responses toward obtaining devalued outcomes, thereby indicating a shift in the balance toward habitual responding and/or away from goal-directed responding. Additionally, we observed that acute stressinduced cortisol reactivity plays a role in this shift since cortisol responders, cortisol nonresponders, and no-stress controls differed in their number of responses made toward valuable and devalued outcomes.

The current results accord well with previously mentioned studies, showing that acute stress induces a shift away from goal-directed control and toward habitual control (Fournier et al., 2017; Schwabe \& Wolf, 2010, 2011; Smeets et al., 2019; Wirz et al., 2018). Additionally, we observed that stress-induced cortisol reactivity plays a role in this shift in balance. This corresponds to our previous findings (Smeets et al., 2019) and another recent study, showing that acute stress exposure postlearning was associated with better retrieval of S-R memories (Goldfarb, 

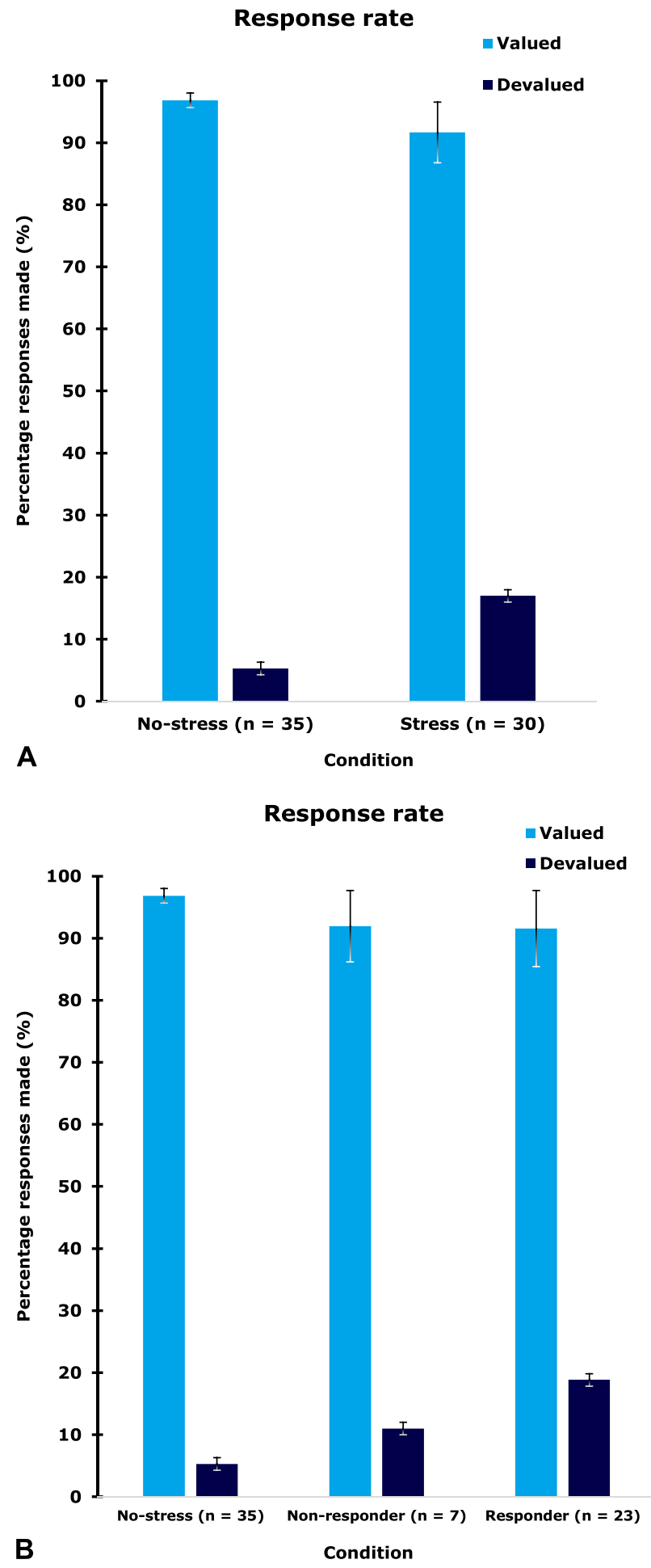

Figure 5. (A) Performance on the slips-of-action stage for the no-stress control group and stress group in mean percentage responses made for valuable and devalued outcomes separately $( \pm S E)$. Habitual responding is indicated by a higher number of responses made toward devalued outcomes. (B) Performance on the slips-of-action stage for the no-stress control group, cortisol nonresponders, and cortisol responders in mean percentage responses made for valuable and devalued outcomes separately $( \pm S E)$. Habitual responding is indicated by a higher number of responses made toward devalued outcomes.
Mendelevich, \& Phelps, 2017). It should be noted that in both experiments of our previous study (Smeets et al., 2019), cortisol responders made significantly more responses toward devalued outcomes relative to nonresponders and no-stressed controls, with the (stressed) nonresponder group descriptively making the fewest responses. In contrast, in the current study, the stress group as a whole responded more often toward devalued outcomes compared to no-stressed controls while there were less marked differences between responders and nonresponders. This could be explained by the fact that in our 2019 study, cortisol levels of the cortisol responder group were already significantly higher at the start of the slips-ofaction phase compared to those of cortisol nonresponders. In contrast, in the current study, cortisol levels were only significantly elevated in the cortisol responder group just after the slips-of-action phase. Thus, the less pronounced difference between cortisol responders and nonresponders in responding toward devalued outcomes in the current study could be attributed to smaller differences in cortisol levels. It therefore further highlights the previously drawn conclusion (Smeets et al., 2019) that stress-induced cortisol reactivity may play a crucial role in shifting the balance between the two systems of responding in instrumental learning.

It is important to note that outcome devaluation paradigms have inherent limitations of their own and that not all induce significant results. For example, Watson and de Wit (2018) were unable to elicit habitual responding through overtraining in five separate studies. Moreover, recently, it has been suggested that these paradigms do not measure habitual behavior per se but are an approximation of the degree of involvement of the goal-directed system (De Houwer et al., 2018; Foerde, 2018; Watson \& de Wit, 2018; see also Ossewaarde et al., 2011). In their paper, De Houwer and colleagues (2018) rightly state that outcome devaluation paradigm essentially requires an absence of an effect to show habit formation. Namely, habits are reflected by an insensitivity to devaluation, and therefore, no effect of devaluation on pressing toward devalued outcomes would demonstrate perfect habitual performance. However, we cannot be sure that the absence of change is not due to other factors, such as a reduction in influence of the goal-directed system, or a change in strategy. In other words, current paradigms seem unable to deduce whether responding to devalued outcomes is caused by a strong habit system or a weak goal-directed system. Others corroborate this (Foerde, 2018; Watson \& de Wit, 2018), and an fMRI study of Ossewaarde et al. (2011) demonstrated that acute stress reduced reward-related responses in an area associated with goal-directed control (vmPFC) rather than influencing the striatum. Current paradigms do however seem able to estimate the balance between the 
two systems, as illustrated by numerous fMRI studies using these paradigms (e.g., Watson et al., 2018). Likewise, our results show that stress versus control as well as responder versus nonresponder versus control comparisons led to significant differences in response rates toward valuable and devalued outcomes. Namely, participants exposed to acute stress appear to press more toward devalued outcomes compared to no-stress controls. This seems to fit well in the current discussion of habitual behavior, as our findings could be explained in light of a decreased involvement of the goal-directed system, an increased involvement of the habit system, or likely a combination of both. As Watson and de Wit (2018) have suggested, other manipulations are needed in combination with overtraining to further explore a decreased involvement of the goal-directed system, such as time pressure, acute stress induction, or a concurrent cognitive load. Indeed, our setup was not optimized to correctly compare reaction times, so future studies into a potential speed-accuracy trade-off in outcome devaluation tasks should be conducted.

The current study has a number of specific limitations. First, we included women who used and women who did not use hormonal contraceptives and did not control for menstrual phase in female participants, which is known to affect cortisol responses to acute stress (Kudielka, Hellhammer, \& Wüst, 2009), and may also have influenced the stress-induced shift in balance between goaldirected and habitual responding. Future research could clarify the role of hormonal contraceptives and menstrual phase in outcome devaluation paradigms by considering it in the design of the study. Furthermore, we unfortunately did not record willingness-to-eat ratings for both food types individually, so it is difficult to assess a potential improvement in a specific devaluation of one of the food types but not the other (even though devaluation did successfully affect responding in the slips-of-action stage). Last, dividing the stress group into cortisol nonresponders and cortisol responders inherently reduces the number of participants in each group, thereby reducing power. This could also play a role in none of our follow-up comparisons in the slipsof-action stage surviving stringent statistical correction.

It is nevertheless important to study the effects of acute and chronic stress on instrumental learning more systematically, especially in clinical groups. A number of studies have indicated that, for example, in eating disorders, such as binge eating disorder and bulimia nervosa, the balance between habitual and goal-directed responding is distorted. Additionally, brain areas are altered such as the orbitofrontal cortex and striatum associated with the two systems and induce a hyporesponsiveness to food stimuli but devalue the actual reward value (Balodis, Grilo, \& Potenza, 2015; Berner, Winter, Matheson,
Benson, \& Lowe, 2017; Voon et al., 2015). In addition, stress is a major risk factor for developing these disorders and seems to be involved in maintaining it (e.g., Razzoli, Pearson, \& Crow, 2017; for an overview of these principles in binging disorders, see Hartogsveld, Quaedflieg, van Ruitenbeek \& Smeets, 2020). Taken together, this study shows that altering specific characteristics of the outcome devaluation paradigm, such as contingency rate, does not seem to change the significant impact of acute stress on the balance between habitual and goal-directed responding. It also shows that a 2-day paradigm can be safely employed, since the effects of acute stress seem robust against changes to the learning stage. Note that our results demonstrate an effect of acute stress on both valuable and devalued outcomes, variables traditionally implicated in goal-directed and habitual responding, respectively. This illustrates the need for systematic research in the exact role of each system, as recently discussed by a number of authors (De Houwer et al., 2018; Foerde, 2018; Watson \& de Wit, 2018). Future research may thus focus on investigating the exact role of instrumental conditioning, habitual responding, and stress in developing and maintaining (eating) disorders and on creating a new paradigm that can disentangle the roles of the goal-directed and habit systems.

\section{References}

Alvares, G. A., Balleine, B. W., \& Guastella, A. J. (2014). Impairments in goal-directed actions predict treatment response to cognitivebehavioral therapy in social anxiety disorder. PLoS ONE, 9, e94778. https://doi.org/10.1371/journal.pone.0094778

Balodis, I. M., Grilo, C. M., \& Potenza, M. N. (2015). Neurobiological features of binge eating disorder. CNS Spectrums, 20, 557-565. https://doi.org/10.1017/S1092852915000814

Berner, L. A., Winter, S. R., Matheson, B. E., Benson, L., \& Lowe, M. R. (2017). Behind binge eating: A review of food-specific adaptations of neurocognitive and neuroimaging tasks. Physiology \& Behavior, 176, 59-70. https://doi.org/10.1016/j.physbeh.2017.03. 037

De Houwer, J., Tanaka, A., Moors, A., \& Tibboel, H. (2018). Kicking the habit: Why evidence for habits in humans might be overestimated. Motivation Science, 4(1), 50-59. https://doi.org/10. 1037/mot0000065

de Wit, S., Niry, D., Wariyar, R., Aitken, M. R. F., \& Dickinson, A. (2007). Stimulusoutcome interactions during instrumental discrimination learning by rats and humans. Journal of Experimental Psychology: Animal Behavior Processes, 33(1), 1-11. https://doi.org/10.1037/0097-7403.33.1.1

de Wit, S., Watson, P., Harsay, H. A., Cohen, M. X., van de Vijver, I., \& Ridderinkhof, K. R. (2012). Corticostriatal connectivity underlies individual differences in the balance between habitual and goal-directed action control. The Journal of Neuroscience, 32, 12066-12075. https://doi.org/10.1523/JNEUROSCI.108812.2012 
Dickerson, S. S., \& Kemeny, M. E. (2004). Acute stressors and cortisol responses: A theoretical integration and synthesis of laboratory research. Psychological Bulletin, 130, 355-391. https://doi.org/10.1037/0033-2909.130.3.355

Dudai, Y. (2004). The neurobiology of consolidations, or, how stable is the engram? Annual Review of Psychology, 55, 51-86. https:// doi.org/10.1146/annurev.psych.55.090902.142050

Erdfelder, E., Faul, F., \& Buchner, A. (1996). GPOWER: A general power analysis program. Behavior Research Methods, Instruments, \& Computers, 28(1), 1-11. https://doi.org/10.3758/BF03203630

Foerde, K. (2018). What are habits and do they depend on the striatum? A view from the study of neuropsychological populations. Current Opinion in Behavioral Sciences, 20, 17-24. https://doi.org/10.1016/j.cobeha.2017.08.011

Fournier, M., d'Arripe-Longueville, F., \& Radel, R. (2017). Effects of psychosocial stress on the goal-directed and habit memory systems during learning and later execution. Psychoneuroendocrinology, 77, 275-283. https://doi.org/10.1016/j.psyneuen. 2016.12.008

Friedel, E., Koch, S. P., Wendt, J., Heinz, A., Deserno, L., \& Schlagenhauf, F. (2014). Devaluation and sequential decisions: Linking goal-directed and model-based behavior. Frontiers in Human Neuroscience, 8, 587. https://doi.org/10. 3389/fnhum.2014.00587

Goldfarb, E. V., Mendelevich, Y., \& Phelps, E. A. (2017). Acute stress time-dependently modulates multiple memory systems. Journal of Cognitive Neuroscience, 29, 1877-1894. https://doi.org/10. 1162/jocn_a_01167

Hartogsveld, B., Quaedflieg, C. W. E. M., van Ruitenbeek, P., \& Smeets, T. (2020, April 19). Volumetric and connectivity changes in brain networks associated with reward sensitivity, cognitive control, and negative affect in binge eating disorder and bulimia nervosa. PsyArXiv preprint. https://doi.org/10.31234/osf.io/vdha9

Hermans, E. J., Henckens, M. J. A. G., Joëls, M., \& Fernández, G. (2014). Dynamic adaptation of large-scale brain networks in response to acute stressors. Trends in Cognitive Sciences, 37, 304-314. https://doi.org/10.1016/j.tins.2014.03.006

Holm, S. (1979). A simple sequentially rejective multiple test procedure. Scandinavian Journal of Statistics, 6, 65-70. Retrieved from http://www.jstor.org/stable/4615733

Joëls, M., \& Baram, T. Z. (2009). The neuro-symphony of stress. Nature Reviews Neuroscience, 10, 459-466. https://doi.org/10. 1038/nrn2632

Joëls, M., Fernandez, G., \& Roozendaal, B. (2011). Stress and emotional memory: A matter of timing. Trends in Cognitive Sciences, 15, 280-288. https://doi.org/10.1016/j.tics.2011.04.004

Kudielka, B. M., Hellhammer, D. H., \& Wüst, S. (2009). Why do we respond so differently? Reviewing determinants of human salivary cortisol responses to challenge. Psychoneuroendocrinology, 34, 2-18. https://doi.org/10.1016/j.psyneuen.2008.10.004

Leys, C., Ley, C., Klein, O., Bernard, P., \& Licata, L. (2013). Detecting outliers: Do not use standard deviation around the mean, use absolute deviation around the median. Journal of Experimental Social Psychology, 49, 764-766. https://doi.org/10.1016/j.jesp.2013.03.013

Miller, R., Plessow, F., Kirschbaum, C., \& Stalder, T. (2013). Classification criteria for distinguishing cortisol responders from nonresponders to psychosocial stress: Evaluation of salivary cortisol pulse detection in panel designs. Psychosomatic Medicine, 840, 832-840. https://doi.org/10.1097/PSY.0000000000000002

O'Doherty, J. P., Cockburn, J., \& Pauli, W. M. (2017). Learning, reward, and decision making. Annual Review of Psychology, 68, 73-100. https://doi.org/10.1146/annurev-psych-010416-044216

Ossewaarde, L., Qin, S., van Marle, H. J. F., van Wingen, G. A., Fernández, G., \& Hermans, E. J. (2011). Stress-induced reduction in reward-related prefrontal cortex function. Neuroimage, 55(1), 345-352. https://doi.org/10.1016/j.neuroimage.2010.11.068
Otto, A. R., Raio, C. M., Chiang, A., Phelps, E. A., \& Daw, N. D. (2013) Working-memory capacity protects model-based learning from stress. Proceedings of the National Academy of Sciences, 110, 20941-20946. https://doi.org/10.1073/pnas.1312011110

Pruessner, J. C., Dedovic, K., Khalili-Mahani, N., Engert, V., Pruessner, M., Buss, C., ... Lupien, S. (2008). Deactivation of the limbic system during acute psychosocial stress: Evidence from positron emission tomography and functional magnetic resonance imaging studies. Biological Psychiatry, 63, 234-240. https://doi.org/10.1016/j.biopsych.2007.04.041

Pruessner, J. C., Kirschbaum, C., Meinlschmid, G., \& Hellhammer, D. H. (2003). Two formulas for computation of the area under the curve represent measures of total hormone concentration versus time-dependent change, 28, 916-931. https://doi.org/10. 1016/S0306-4530(02)00108-7

Quaedflieg, C. W. E. M., Meyer, T., van Ruitenbeek, P., \& Smeets, T. (2017). Examining habituation and sensitization across repetitive laboratory stress inductions using the MAST. Psychoneuroendocrinology, 77, 175-181. https://doi.org/10.1016/j.psyneuen. 2016.12.009

Quaedflieg, C. W. E. M., \& Schwabe, L. (2018). Memory dynamics under stress. Memory, 26, 364-376. https://doi.org/10.1080/ 09658211.2017 .1338299

Quaedflieg, C. W. E. M., Stoffregen, H., Sebalo, I., \& Smeets, T. (2019). Stress-induced impairment in goal-directed instrumental behaviour is moderated by baseline working memory. Neurobiology of Learning and Memory, 158, 42-49. https://doi.org/10. 1016/j.nlm.2019.01.010

Razzoli, M., Pearson, C., Crow, S., \& Bartolomucci, A. (2017). Stress, overeating and obesity: Insights from human studies and preclinical models. Neuroscience \& Biobehavioral Reviews. 76, 154-162. https://doi.org/10.1016/j.neubiorev.2017.01.026

Rousseeuw, P. J., \& Croux, C. (1993). Alternatives to the median absolute deviation. Journal of the Acoustical Society of America, 88, 1273-1283. https://doi.org/10.1080/01621459. 1993.10476408

Schultz, W. (2015). Neuronal reward and decision signals: From theories to data. Physiological Reviews, 95(3), 853-951. https:// doi.org/10.1152/physrev.00023.2014

Schwabe, L. (2017). Memory under stress: From single systems to network changes. European Journal of Neuroscience, 45, 478-489. https://doi.org/10.1111/ejn.13478

Schwabe, L., \& Wolf, O. T. (2009). Stress prompts habit behavior in humans. Journal of Neuroscience, 29, 7191-7198. https://doi.org/ 10.1523/jneurosci.0979-09.2009

Schwabe, L., \& Wolf, O. T. (2010). Socially evaluated cold pressor stress after instrumental learning favors habits over goaldirected action. Psychoneuroendocrinology, 35, 977-986. https://doi.org/10.1016/j.psyneuen.2009.12.010

Schwabe, L., \& Wolf, O. T. (2011). Stress-induced modulation of instrumental behavior: From goal-directed to habitual control of action. Behavioural Brain Research, 219, 321-328. https://doi. org/10.1016/j.bbr.2010.12.038

Schwabe, L., Wolf, O. T., \& Oitzl, M. S. (2010). Memory formation under stress: Quantity and quality. Neuroscience and Biobehavioral Reviews, 34, 584-591. https://doi.org/10.1016/j. neubiorev.2009.11.015

Seehagen, S., Schneider, S., Rudolph, J., Ernst, S., \& Zmyj, N. (2015). Stress impairs cognitive flexibility in infants. Proceedings of the National Academy of Sciences, 112, 12882-12886. https://doi. org/10.1073/pnas.1508345112

Sheffield, V. F. (1949). Extinction as a function of partial reinforcement and distribution of practice. Journal of Experimental Psychology, 39(4), 511-526. https://doi.org/10.1037/h0057242

Shields, G. S., Sazma, M. A., McCullough, A. M., \& Yonelinas, A. P. (2017). The effects of acute stress on episodic memory: A meta- 
analysis and integrative review. Psychological Bulletin, 143, 636-675. https://doi.org/10.1037/bul0000100

Shilton, A. L., Laycock, R., \& Crewther, S. G. (2017). The Maastricht Acute Stress Test (MAST): Physiological and subjective responses in anticipation, and post-stress. Frontiers in Psychology, 8, 567. https://doi.org/10.3389/fpsyg.2017.00567

Smeets, T. (2011). Acute stress impairs memory retrieval independent of time of day. Psychoneuroendocrinology, 36, 495-501. https://doi.org/10.1016/j.psyneuen.2010.08.001

Smeets, T., Cornelisse, S., Quaedflieg, C. W. E. M., Meyer, T., Jelicic, M., \& Merckelbach, H. (2012). Introducing the Maastricht Acute Stress Test (MAST): A quick and non-invasive approach to elicit robust autonomic and glucocorticoid stress responses. Psychoneuroendocrinology, 37, 1998-2008. https://doi.org/10.1016/ j.psyneuen.2012.04.012

Smeets, T., Otgaar, H., Candel, I., \& Wolf, O. T. (2008). True or false? Memory is differentially affected by stress-induced cortisol elevations and sympathetic activity at consolidation and retrieval. Psychoneuroendocrinology, 33, 1378-1386. https://doi. org/10.1016/j.psyneuen.2008.07.009

Smeets, T., van Ruitenbeek, P., Hartogsveld, B., \& Quaedflieg, C. W. E. M. (2019). Stress-induced reliance on habitual behavior is moderated by cortisol reactivity. Brain and Cognition, 133, 60-71. https://doi.org/10.1016/j.bandc.2018.05.005

Ulrich-Lai, Y. M., \& Herman, J. P. (2009). Neural regulation of endocrine and autonomic stress responses. Nature Reviews Neuroscience, 10, 397-409. https://doi.org/10.1038/nrn2647

Voon, V., Baek, K., Enander, J., Worbe, Y., Morris, L. S., Harrison, N. A., ... Daw, N. (2015). Motivation and value influences in the relative balance of goal-directed and habitual behaviours in obsessive-compulsive disorder. Translational Psychiatry, 5, e670. https://doi.org/10.1038/tp.2015.165

Watson, P., \& de Wit, S. (2018). Current limits of experimental research into habits and future directions. Current Opinion in Behavioral Sciences, 20, 33-39. https://doi.org/10.1016/j.cobeha.2017.09.012

Watson, P., van Wingen, G., \& de Wit, S. (2018). Conflicted between goal-directed and habitual control, an $\mathrm{fMRI}$ investigation. ENeuro, 5, 1-11. https://doi.org/10.1523/eneuro.0240-18.2018

Weinstock, S. (1954). Resistance to extinction of a running response following partial reinforcement under widely spaced trials. Journal of Comparative and Physiological Psychology, 47(4), 318-322. https://doi.org/10.1037/h0054129

Wirz, L., Bogdanov, M., \& Schwabe, L. (2018). Habits under stress: Mechanistic insights across different types of learning. Current
Opinion in Behavioral Sciences, 20, 9-16. https://doi.org/10.1016/ j.cobeha.2017.08.009

\section{History}

Received December 10, 2019

Revision received April 24, 2020

Accepted May 2, 2020

Published online July 30, 2020

\section{Acknowledgments}

We are especially thankful to Clara Courboin, Florine Remacle, Loriane Verleye, Kemala Cut Nurul, and Anneke Terneusen for their help in collecting the data.

\section{Publication Ethics}

This study was approved by the standing ethics committee of the Faculty of Psychology and Neuroscience, Maastricht University, complying with the Declaration of Helsinki (v. 2013).

\section{Open Data}

All data and codes are available from the corresponding author using the following link: https://hdl.handle.net/10411/B9TDBW. Materials for purpose of replicating the procedure or reproducing the results can be made available on request by contacting the corresponding author.

\section{Funding}

This work was supported by the Netherlands Organization for Scientific Research (Nederlandse Organisatie voor Wetenschappelijk Onderzoek, NWO) to Tom Smeets (grant number 45214-003).

\section{ORCID}

Bart Hartogsveld

(i) https://orcid.org/0000-0001-6929-3946

\section{Bart Hartogsveld}

Department of Clinical Psychological Science

Faculty of Psychology and Neuroscience

Maastricht University

Universiteitssingel 40

6229 ER Maastricht

The Netherlands

bart.hartogsveld@maastrichtuniversity.nl 